\title{
Research on Application of Green Concepts in Interior Design
}

\author{
Ni Ming \\ Suqian College,Suqian,223800,P.R.CHINA \\ nimingnm@126.com
}

\begin{abstract}
Keywords: Green Concept, Interior Design, Green Environmental Technology
\end{abstract}
\begin{abstract}
With the continuous development of society, economy and science and technology, more and more people are in the pursuit of ecological development and energy saving mode of life, green concept has gradually been people's attention in the interior design, which is to achieve ecological development, and nature effective way to live in harmony. Green interior design using green design concepts and design methods for people to create a comfortable and livable interior space to meet people for the pursuit of healthy nature, become the interior design concept of the leading, green interior design by improving the spatial layout, select the green material optimization measures, improve the indoor environment, compared to the traditional design, green interior design more focused on the traditional and into the modern style, pay more attention to the practicality of decoration, improve space utilization at the same time fully reflect the humanistic care, green interior design and sustainable development. People in the interior design more and more inclined to use the power of nature, reduce the interference and destruction of the environment. The extensive application of green design concept has become one of the trends in interior design.
\end{abstract}

\section{Theoretical Introduction of Green Concept}

Green concept is with the people's awareness of environmental protection and the emergence of the concept of interior design, the specific requirements in the interior design, to consider the product life, the use of functional, quality and other factors, especially the focus on the impact of the indoor environment The Green design concept Focus on resource conservation, in the indoor environment to create, focusing on the optimization of resources, reduce indoor space energy loss, in the interior design of the implementation of energy conservation and environmental protection development.

According to the principle of local conditions, green design concept and the concept of sustainable development in China coincide, are stressed to achieve the sustainable development of the interior design industry, and improve the efficiency of the industry's energy use. People have significant differences in the requirements of the living environment, combined with the actual situation of the construction, residential needs and building standards for different classification planning. In addition, to take into account the principle of integrity, green design concept to consider the material water saving, energy saving, building materials and other issues, do a good job in indoor space planning work, and pay attention to the construction of indoor ecological environment, to achieve a holistic green energy ${ }^{[1]}$.

Interior green design is to provide people with a healthy, safe, convenient and comfortable indoor living space design. Through the layout of interior space, the use of decorative materials, the mediation of indoor physical environment and the coordination of indoor colors at the same time, the full use of energy, greatly reduce pollution and other issues on the design of the primary position to meet the residents of physical, Psychological, health and other requirements. Therefore, the indoor "green design" is not only a technical layer of consideration, more importantly, a concept of change. It requires designers to interior design concepts, design methods as the starting point to achieve the protection of the environment, care for life, and needs of the green action.

\section{Interior Green Design Principles}

Green design is a major change in the concept of interior designs, and the core is designed to meet the ecological environment of the virtuous circle of the indoor space environment. And resolutely 
put an end to the use of inferior materials can't be large and the use of synthetic materials, as far as possible the use of some less harmful gases, the harm to the human body of small materials, these new materials applied to the interior design, energy and environmental protection objectives ${ }^{[2]}$. Fig. 1 shows interior green design principles.

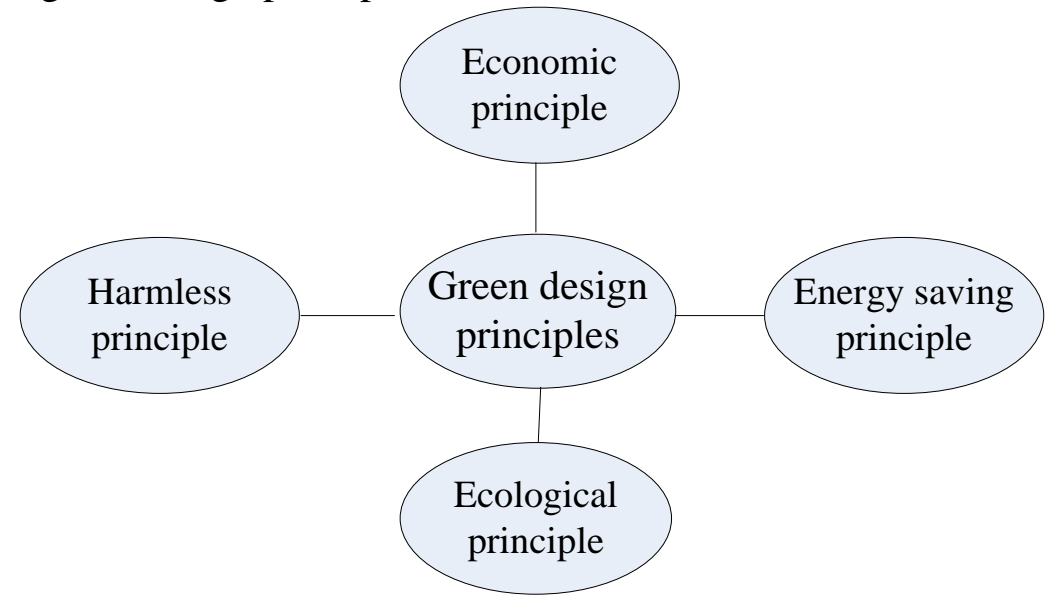

Fig. 1.Interior green design principles

Green design is also known as eco-design, sustainable design. The basic idea is that a series of environmental parameters such as winning, detachability, maintainability, renewable, reusability can be included in the product design process, and the environmental performance as the product design goals and starting point of the design process. When these parameters meet the requirements, and then consider to ensure that the product cycle and performance, and strive to minimize the impact on environmental factors, thereby reducing the consumption of resources to achieve sustainable development of strategic objectives.

Harmless principle: refers to the ornaments on the indoor environment and people without harm, the focus is reflected in the choice of building materials, green material selection should be low energy consumption, pollution-free, non-toxic energy - saving materials. Ecological principles: a lot of materials do not have the regeneration, and modern society on the use of materials is too large, indoor green design eco-principles include the balance of ecosystems and the conservation of various natural resources, design, try to consider the ecological, repeatability, intelligence and functionality. Energy-saving principle: refers to all materials and materials to maximize the use to reduce consumption and reduce the wood, in the use of natural resources must be considered: whether the excessive use of building materials in natural resources; of the building materials can achieve renewable resources and so on. The principle of beauty: refers to the interior decoration to be artistic, with a unique aesthetic taste. Economic principles: economic principles to meet the harmless, ecological, energy saving, aesthetic on the basis of the principle ${ }^{[3]}$.

\section{Application of Green Design Concept in Interior Design}

Interior green design concept has been deeply rooted in the people, especially in the pursuit of natural, harmonious, low-carbon, environmentally friendly decoration style trends, green design concept has become the focus of interior design. A comprehensive understanding of the concept of interior design green design, and by improving the spatial layout, choose a good interior materials and heating technology, while optimizing the indoor environment, the introduction of natural elements to enhance the comfort of interior design ${ }^{[4]}$.

The key to the interior design is to improve the layout of the interior space, which is the key to the interior design work. The layout of the interior space should meet the needs of people's life and apply the green design concept to improve the effectiveness of the design work and make the interior space more rational. Building decoration used in the polymer materials are more, first of all to ensure that it has a high durability, and drying speed, while to have wear, corrosion resistance and other properties; heating technology is the focus of interior design work to consider, heating The choice of technology should be consistent with the indoor structure of space performance, green 
design concept to promote the heating technology innovation.

Interior environment optimization, including ventilation, lighting, sound, etc., which is directly related to people's normal life factors. For a ventilated environment, the green design concept requires that the design of the ventilation window be aerodynamically optimized to optimize the indoor environment and achieve optimal living comfort. Finally, the noise pollution control, strengthen the indoor anti-noise ability, to improve the indoor sound insulation effect, to ensure the ecological environment of the indoor environment. Indoor greening design is one of the important works in green building, because the indoor green design is directly related to people's quality of living. Therefore, in the room to configure a reasonable green design, you can in the space within the appropriate vegetation decoration, optimize the indoor air environment, while ensuring the role of decorative space. Fig.2 shows interior environment green effect renderings.

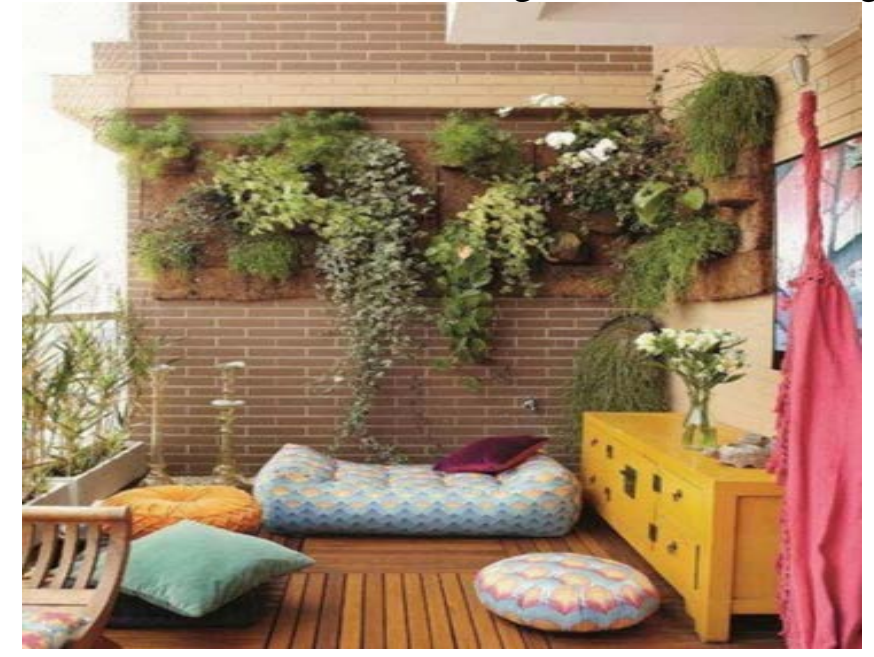

Fig. 2.The interior environment green effect renderings

\section{Green Environmental Technology}

The use of green building materials for interior decoration is the focus of green design, green building materials with non-polluting, renewable and energy-saving advantages. When used, need to check whether the national environmental labeling certification, with or without environmental certification mark, there are a lot of environmentally friendly pollution-free green materials, environmental performance are more assured. Green decorative materials require the use of decorative functional properties, green properties, the principle of combining economy, taking into account the environmental performance of decorative materials, the use of performance, economic performance, process performance and other factors, the extent of the impact of the environment. Green decorative materials should not discharge or rarely emissions of harmful ingredients, the use of good durability, management and maintenance convenience ${ }^{[5]}$.

Color decorative materials should not discharge or rarely emissions of harmful ingredients, the use of good durability, management and maintenance facilities. In general, the more complex the manufacturing process, the more complex the process of decorative materials, the need to consume more energy, where to maintain maintenance, durability, based on the choice of low energy consumption of materials, the best use of natural materials. Similarly, taking into account transport and other issues, local production materials than the field of imported materials, low energy consumption, the destruction of the ecological environment even smaller. In the decoration technology, to try to avoid on-site production, which not only waste human and material resources, more importantly, there is no protection and recovery measures of air, dust and other environmental pollution.

Energy saving is an important problem that can't be ignored in interior design. It is very important to solve the problem of energy saving by means of technical measures, such as lighting, ventilation, heat preservation and lighting technology. Intelligent building materials refers to building materials that can perceive the surrounding environment, such as temperature, humidity, 
pressure, electromagnetic, sound and other changes and change their own performance parameters in time to make corresponding countermeasures. Such as electromagnetic shielding concrete can reduce the pollution of electromagnetic radiation, humidified concrete can control the indoor environment humidity, intelligent latex paint can automatically adjust the brightness automatically adapt to changes in the environment. Common greening technology has indoor greening, roof greening, window greening, the introduction of green plants in the indoor environment, green plants to absorb carbon monoxide, the release of oxygen, play a landscaping environment and the role of air purification.

\section{Conclusions}

With the rapid development of science and technology, people continue to deepen the understanding of natural, energy saving and environmental protection and other green design concepts are used in interior design. In the interior design, the application of green design concept can meet people's ecological development, healthy living environment, energy saving and environmental protection and other needs. In the practice of interior design, designers should adhere to the people-oriented, adhere to the actual starting, pay attention to a reasonable layout of space, pay attention to the use of green materials, focus on saving energy resources, and strive to create a more comfortable and harmonious indoor environment. Indoor green design has been gradually recognized and accepted, the use of green furniture and green materials are also popular, green space layout has gradually been accepted by people, green design concept in the interior design application will be more extensive and mature.

\section{Reference}

[1] WU Yi-jun. On the integration of green concept and interior design [J]. Friends of Science, 2011 (6): 10-11.

[2] Zong Xiao ping. Study on Green Design of Residential Buildings [J]. Fujian Architecture, 2012 (8): 31

[3] Zhou Wei. Green decoration in residential decoration [J]. Residential Science and Technology, 2012 (12): 14-15.

[4] Li Sha. Explore the architectural interior design green design concept [J], Science and Technology Information, 2012 (18): 45-46.

[5] Xiu Jian ping. Green Notions and practice in the interior design of the big stage [J], 2012 (6): 90-90. 